\title{
Trabalhonecessário
}

Issn: 1808 - 799X

ano 14, número $23-2016$

MEMÓRIA E DOCUMENTOS

\section{DITADURA MILITAR E TRABALHO DOCENTE}

\author{
Moacyr Salles ${ }^{1}$
}

Inêz Stampa²

\section{Introdução}

A ditadura militar foi um período conturbado da história brasileira. Essa época é marcada por vários Atos Institucionais que colocavam em prática a censura, a perseguição política, a supressão de direitos constitucionais, a falta total de democracia e a repressão àqueles que, porventura, fossem contrários ao regime militar. Os direitos fundamentais naquela época sequer eram respeitados.

A censura contra os políticos, intelectuais, comunicadores, imprensa, artistas e educadores era efetiva. Tudo que fosse ligado ao público era devidamente verificado, censurado, cortado e proibido, de acordo com os interesses ditatoriais. Assim funcionava no tocante aos livros, telenovelas, peças

\footnotetext{
${ }^{1}$ Graduado em Pedagogia pela Universidade do Estado do Rio de Janeiro (UERJ), mestre em Educação pela Universidade Federal Rural do Rio de Janeiro (UFRRJ) e doutorando em Serviço Social pela Pontifícia Universidade Católica do Rio de Janeiro (PUC-Rio). Atua como pedagogo na Universidade Federal Fluminense (UFF). E-mail: mramos@id.uff.br

2 Assistente social e socióloga, doutora em Serviço Social pela PUC-Rio, professora adjunta do Departamento de Serviço Social e do Programa de Pós-Graduação em Serviço Social da PUCRio, do qual é atualmente coordenadora. Servidora do Arquivo Nacional/Ministério da Justiça, onde coordena o Centro de Referência das Lutas Políticas no Brasil (1964-1985) - Memórias Reveladas. E-mail: inestampa@ig.com.br
} 


\section{Trabalhonecessário}

Issn: 1808 - 799X

ano 14 , número $23-2016$

de teatro, músicas e até mesmo às aulas ministradas nas escolas e universidades.

Nessa época, houve flagrante violação aos direitos fundamentais mínimos dos cidadãos, especialmente no que se referia ao direito à liberdade. No entanto, a luta contra a ditadura de fato ocorreu, principalmente junto aos jovens, através dos movimentos estudantis, que ganharam força em 1968, e também junto aos professores universitários e demais trabalhadores, inclusive os de chão de fábrica, através das suas organizações, ocorridas no próprio local de trabalho, ainda que incipientes.

Com o Ato Institucional n. 5, em 1968, houve o recesso do Congresso Nacional, a legalidade à repressão, o que permitiu que o presidente da República pudesse cassar mandatos eletivos, suspender direitos políticos de qualquer cidadão que se mostrasse insatisfeito com o regime militar, além de corroborar com o confisco de bens e a suspensão da garantia do habeas corpus.

A tortura foi utilizada como método covarde e vil pela ditadura militar brasileira. Deixou sequelas irreparáveis tanto naqueles que foram impiedosamente torturados, como também nas famílias que não souberam mais notícias dos seus entes que foram abrutalhadamente retirados do seu convívio, sem nenhuma explicação. Segundo Maria Helena Moreira Alves, "a tortura cria um efeito demonstrativo capaz de intimidar os que têm conhecimento de sua existência e inibir a participação política" (1985, p.205).

Assim criou-se uma cultura do medo pela qual se coibiu a participação em atividades de oposição comunitária, sindical ou política. Essa cultura tinha três componentes psicológicos: o silêncio imposto à sociedade pela rigorosa censura; o profundo sentimento de isolamento naqueles que sofriam diretamente a repressão ou exploração econômica; e o sentimento de total desesperança que passou a prevalecer na sociedade (ALVES, 1985, p.205-206). 


\section{Trabalhonecessário}

Issn: 1808 - 799X

ano 14 , número $23-2016$

Nesse contexto, era preciso controlar toda a produção de conhecimento, o que colocou a prática docente sob suspeita. É para exemplificar como o trabalho docente passou a ser controlado de modo sistemático durante a ditadura militar e alimentar o atual debate acerca do tema, que apresentamos dois documentos do acervo do Sistema Nacional de Informações (SNI), guardados no Centro de Referência das Lutas Políticas no Brasil (1964-1985) - Memórias Reveladas, do Arquivo Nacional do Rio de Janeiro ${ }^{3}$.

Importante lembrar que o SNI era o órgão de cúpula do sistema de vigilância política no Brasil e um dos serviços de inteligência mais bem equipados do mundo durante o período em que funcionou (1964-1991). Ele articulava, no Brasil, uma rede composta por centenas de órgãos de vigilância e milhares de agentes e colaboradores, tanto civis quanto militares.

Além do exposto, refletir sobre o controle do trabalho docente no período ditatorial é um exercício indispensável para melhor compreendermos o momento atual, em que a prática docente na perspectiva crítica tem sido alvo de inúmeros ataques. Como exemplo, podemos citar o Movimento Escola Sem Partido, que tem lutado veementemente pela aprovação de leis que criminalizam a prática pedagógica crítica em nome da neutralidade do ato de ensinar, que deve estar presente desde a educação básica até ao ensino superior. Segundo os organizadores desse movimento:

A pretexto de transmitir aos alunos uma "visão crítica" da realidade, um exército organizado de militantes travestidos de professores prevalece-se da liberdade de cátedra e da cortina de segredo das salas de aula para impingir-lhes a sua própria visão de mundo (NAGIB, Movimento Escola Sem Partido) ${ }^{4}$.

\footnotetext{
${ }^{3} \mathrm{O}$ primeiro contato com os documentos apresentados se deu em setembro de 2015, quando buscávamos no acervo do Arquivo Nacional, por intermédio do Centro de Referência Memórias Reveladas, informações sobre a política de educação profissional no período ditatorial.

${ }^{4}$ Conforme consta em seu site, o Movimento Escola Sem Partido foi criado a partir de uma articulação entre pais e alunos preocupados com "o grau de contaminação político-ideológica das
} 


\section{Trabalhonecessário}

Issn: 1808 - 799X

ano 14 , número $23-2016$

Portanto o passado e o presente se encontram e revelam que, além de um processo de transição democrática ainda inconcluso e fragilizado, somos permeados por novas estratégias de controle do trabalho docente de acordo com os interesses do sistema capitalista, também presentes no estado de exceção que vigorou de 1964 a 1985.

\section{O trabalho docente como subversão}

Investigar os mecanismos de resistência docente no período do regime militar é de suma importância não apenas para uma releitura da história da profissão docente no Brasil, mas, principalmente, como prova de que parte desses profissionais lutou avidamente contra a ditadura instaurada em 1964. Trata-se, de modo amplo, de propor novas leituras da luta dos trabalhadores nesse período, esclarecendo que, apesar de alguns cooptados, houve resistência e não passividade generalizada, pois, conforme indica Santana (2014), há uma ideia distorcida de que os trabalhadores, imobilizados, nada fizeram durante a ditadura.

O golpe de 1964 desencadeou uma onda de repressão e de perseguição aos trabalhadores. Evitar manifestações nas ruas, nas fábricas e, de modo geral, a organização dos trabalhadores, era uma necessidade para manter a hegemonia ditatorial. No entanto, havia ainda outras tarefas urgentes: controlar as ideias, impedir a circulação do pensamento marxista, construir nos sujeitos uma visão de

escolas brasileiras". Além de orientações de como identificar um professor doutrinador, o movimento promove palestras e luta pela aprovação de Projetos de Lei (PL) que buscam coibir a "doutrinação" dos alunos por parte dos docentes nas esferas federal, estadual e municipal. Como exemplo temos o PL 867/2015, cujo autor é o deputado Izalci Lucas Ferreira, do PSDB. 


\section{Trabalhonecessário}

Issn: 1808 - 799X

ano 14 , número $23-2016$

mundo que tomasse a ditadura como o único e melhor caminho, esvaziando o debate político.

A necessidade de reprimir as ideias direcionou os olhares para as instituições escolares, especificamente para a prática docente, desde o ensino primário até o ensino superior. $O$ magistério tornou-se uma profissão que demandava controle institucional, pois se configurava como espaço de circulação e construção de conhecimentos que, por vezes, questionavam a ordem ditatorial. Assim, qualquer sinal de resistência ou crítica docente ao golpe era classificada como atividade subversiva e, consequentemente, culminava em violação de direitos humanos, perseguições, constrangimentos, demissões, desaparecimentos e até mortes.

Assim intensificou-se "a caça aos subversivos", com perseguição, prisão, tortura, morte e desaparecimento de diversos militantes docentes e alunos. Além disso, vários reitores foram substituídos por outros indicados pelos militares, a fim de garantir o controle dos processos pedagógicos. Com algumas exceções, os docentes tornaram-se uma categoria de oposição ao regime militar, isso tanto pelo crescimento de integrantes dessa categoria, como pelo arrocho salarial que perdurou todo o regime (FERREIRA JR \& BITTTAR, 2006).

$\mathrm{O}$ controle dos insubordinados se inseria num conjunto de estratégias que pretendia garantir a construção de uma imagem de eficiência, legitimidade, defesa da família, alinhamento cristão e segurança no governo militar, ou seja, tratava-se de um projeto de conformação em torno dos benefícios da ditadura (REZENDE, 2013). Sabe-se que estratégias, como a infiltração de alunos "olheiros" nas aulas, gravação de aulas, cooptação de docentes e gestores, foram utilizadas. A missão era denunciar aos militares qualquer crítica ao regime ditatorial ou que se pautasse no referencial marxista, associado diretamente ao "perigo comunista". É exatamente por se alinhar a esse referencial que uma professora da Universidade de Brasília (UNB) foi considerada subversiva. 


\section{Trabalhonecessário}

Issn: 1808 - 799X

ano 14 , número $23-2016$

O informe no 1587-A4-CIE de 12 de julho de 1983, do Ministério do Exército, tem como assunto "Pregação doutrinária esquerdista na UNB". Trata-se de uma acusação feita à professora de Sociologia da Educação Isaura Belloni Schimidt 5 .

Afirma-se que a professora faz pregação contestando o governo militar e analisa os problemas educacionais brasileiros sob a ótica marxista. Tal prática pedagógica, no caso, é intencional e pública, pois a mesma também declara ser de esquerda.

Consta que em uma de suas aulas a professora Isaura fez um comentário acerca do movimento comunista de $1935^{6}$, tratando seus sujeitos como heróis e não como subversivos, o que desagradou os agentes do SNI. Outra resistência da docente foi, diante de uma greve dos professores da UNB, ter considerado o movimento louvável, o que foi entendido como tentativa de aliciamento de alunos para que se solidarizassem aos docentes em greve.

Segue o documento.

\footnotetext{
${ }^{5}$ Atuou como professora da Faculdade de Educação da UNB, destacando-se na área de avaliação institucional. Faleceu em 25 de outubro de 2010, aos 66 anos de idade.

${ }^{6}$ Também conhecido como Intentona Comunista, teve como base a Aliança Nacional Libertadora (ANL) sob a liderança de Luís Carlos Prestes. O movimento foi considerado ilegal em 1935, porém conseguiu agregar muitos opositores do governo, resultando em levantes contra Getúlio Vargas no Rio de Janeiro, Natal e Recife. Brutalmente reprimido, o movimento foi central para justificar o endurecimento de Vargas contra seus opositores e ainda um crescente massacre a todo o que se diz comunista, que se reflete nos dias atuais (PANDOLFI, 2004).
} 


\section{Trabalhonecessário}

Issn: 1808 - 799X

ano 14, número $23-2016$

$+1$

Mivasstuo Do kKalicho

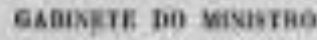

CONFIDEROARL,

BRASTLIA,DI do 12 JUL 1993 it at

\section{INFORME N.'ISP? S/102-A4-CIE}

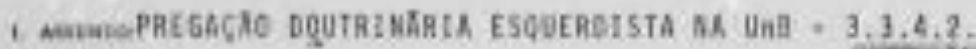

1. conaru CIE

1. avenucson $\mathrm{R}=1$

- turens AC/SEI e DST/MEC

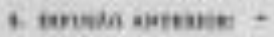

4 someners

\begin{tabular}{|l|}
\hline GEnC6 \\
\hline P14ED2 11a \\
\hline PROTOCOLO
\end{tabular}

1. Sxran:

1. A professora ISAURA EELLOXI SCRIMIOI, $e$ suas aulas te atfologia nu Ualversidade de aRAstLia (Unil) - Depurtanento de teoria e Fundanentos - Disciplitas de Sociologia da Educaçăa, ven,ilstenaticasene,

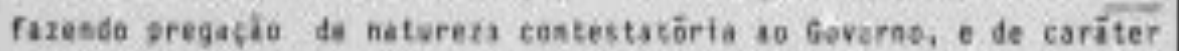
subverstro, esfocando as problenas edrcactanais brestlefras sob a att ca earxistu, dizendo-se, inslustive, "de esquerda".

2. Aesertesente, an suls, at conentar o rortsecto swantsta de 1935, considerou as revoltosos canb herôis + näg subversivos.

3. Par ocasiäo do greve de prafessores, exiltow o novinento, tentando aficier siunos para que estes ficassan solidäriot aes dacentes da UnB.
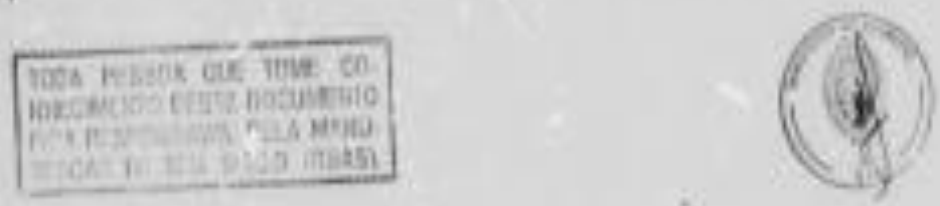


\section{Trabalhonecessário}

Issn: 1808 - 799X

ano 14 , número $23-2016$

Informe no 1587-A4-CIE de 12 de julho de 1983, do Ministério do Exército. Fundo SNI. Acervo do Arquivo Nacional.

Passemos agora ao segundo documento, que se trata de um dossiê. $\mathrm{O}$ encaminhamento secreto ํㅜ 049, do SNI, datado de 04 de março de 1969, tem por objetivo apresentar dados complementares para serem acrescentados à ficha individual no 52/ST/19, de José do Patrocínio Gallotti ${ }^{7}$.

José do Patrocínio Gallotti é descrito como professor de História do Pensamento Econômico da Faculdade de Ciências Econômicas da Universidade Federal de Santa Catarina (UFSC). Além disso, ele era desembargador aposentado do Tribunal de Justiça e advogado.

O professor é acusado de ser o mais antigo comunista de Florianópolis, como também uma pessoa encantada pelas doutrinas marxistas e leninistas. Esse "encantamento" foi percebido através das palestras ministradas por ele. Além disso, pesa a acusação de influenciar a formação política dos alunos e a sua participação em alguns manifestos, inclusive para a legalização do Partido Comunista Brasileiro (PCB). É curioso notar que uma característica da personalidade desse professor, possivelmente por incomodar os que 0 investigavam, é descrita nesse documento: ele era irônico.

$\mathrm{Na}$ sequência, o documento apresenta um histórico em que estão registradas algumas informações sobre a militância do professor, como o resultado de um inquérito instalado na UFSC após 1964.

O inquérito foi aberto, pois José do Patrocínio participou, dentre outros encontros, de reuniões da Frente Operária Estudantil Popular, como também do Encontro de Solidariedade a Cuba, o que foi constatado por meio de perícias grafotécnicas. Conclui-se que o professor não pode continuar no exercício do

\footnotetext{
7 Destacou-se na luta contra o regime ditatorial e na defesa das causas nacionalistas, opondo-se a interferência norte americana no Brasil. Faleceu em 15 de julho de 1985, aos 77 anos.
} 


\section{Trabalhonecessário}

Issn: 1808 - 799X

ano 14 , número $23-2016$

magistério, porque feriu os princípios do Ato Institucional, estando sujeito às sanções da Lei de Segurança Nacional.

Por fim, indica-se que o professor já havia sido preso, acusado de atividades subversivas, logo após do golpe de 1964, ficando recolhido no quartel de Florianópolis de 19 de abril a 25 de junho do mesmo ano.

Segue o dossiê. 


\section{Trabalhonecessário}

Issn: 1808 - 799X

ano 14 , número $23-2016$

\section{PRESIDENCTA DATRPUTLICA}

SERVICO NACIONAL DE INFORMACOES

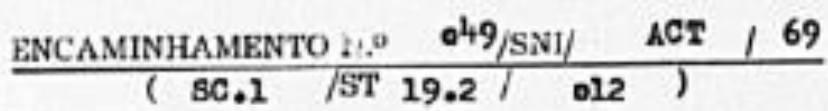

\begin{tabular}{|c|c|c|c|}
\hline DATA & ; & 04.03 .69 & Exemplar $n^{0}$ Ol \\
\hline ASSUNTO & : & COLETA DE DADOS= & \\
\hline REFFRENCIA & $:$ & Ena n $^{0} 30 / \mathrm{skI} / \mathrm{ACT} / 69$, de 02.02 .69 & \\
\hline DISTRIBUIÇAO & : & SNI/ AC. & \\
\hline
\end{tabular}

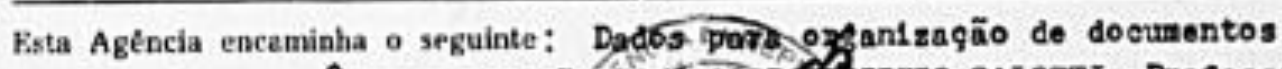

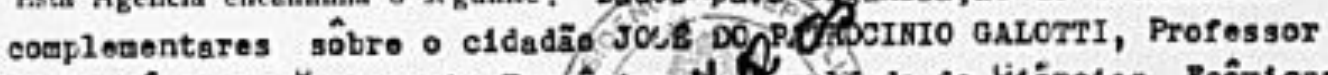

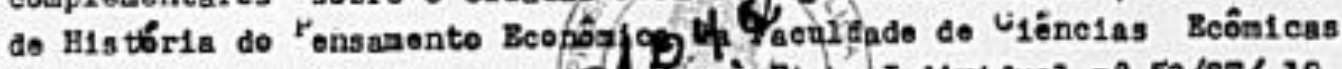

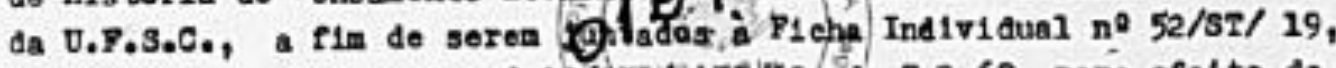
objeto do encazinhamento $n^{0} 30 / 5 N I /$ ACI/69, do 7.2 .69 , para ofe1 to de apll caçäo do Ato Instituctonal ne 5 . 


\section{Trabalhonecessário}

Issn: $1808-799 X$

ano 14, número $23-2016$

TrabalhoNecessário - www.uff.br/trabalhonecessario; Ano 14, № 23/2016. 


\section{Trabalhonecessário}

Issn: 1808 - 799X

ano 14 , número $23-2016$

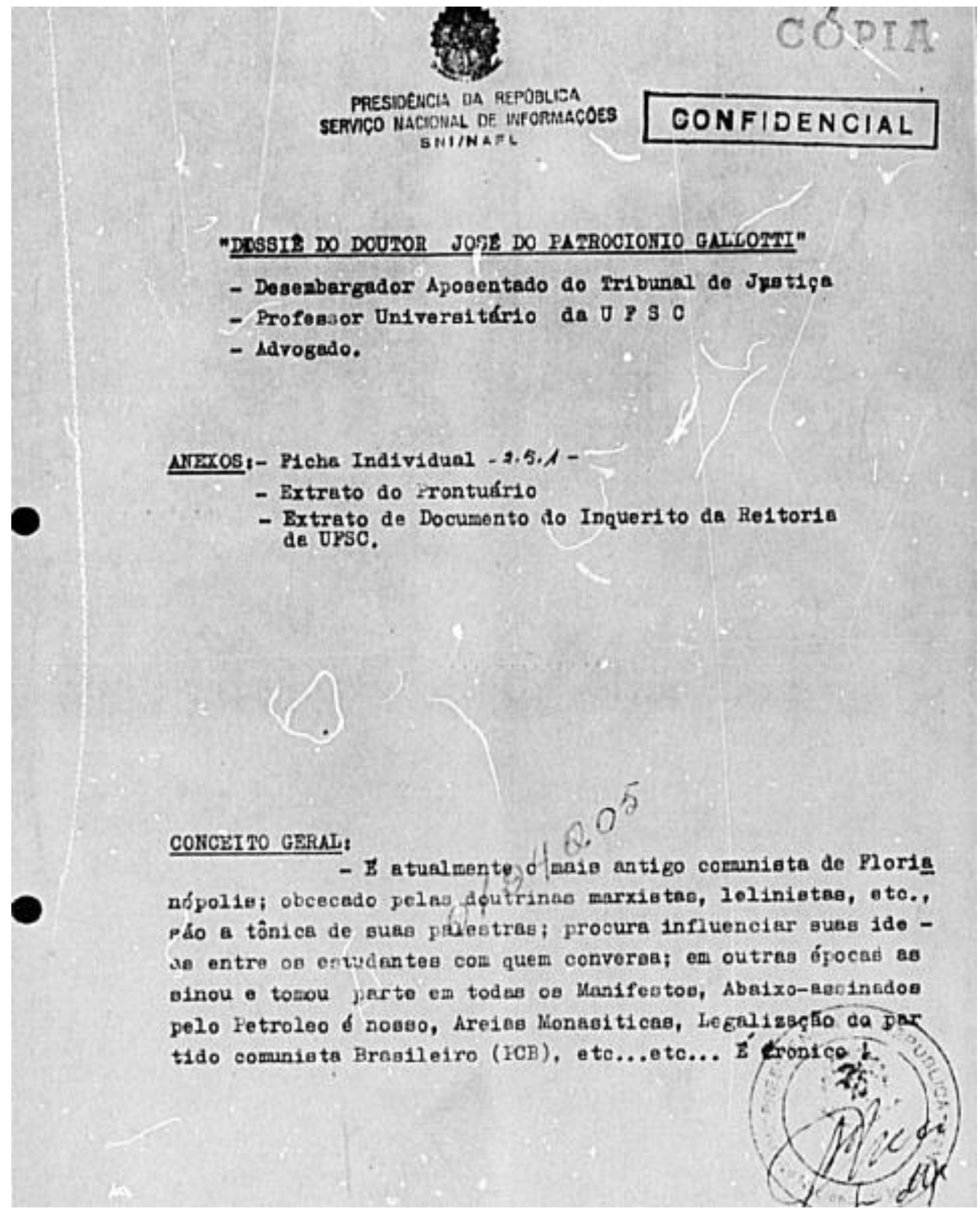

TrabalhoNecessário - www.uff.br/trabalhonecessario; Ano 14, № 23/2016. 


\section{Trabalhonecessário}

Issn: $1808-799 X$

ano 14, número $23-2016$

TrabalhoNecessário - www.uff.br/trabalhonecessario; Ano 14, № 23/2016. 


\section{Trabalhonecessário}

Issn: 1808 - 799X

ano 14, número $23-2016$

PEREIDENCIA DA KEPOBLICA

SERVIÇO NACIONAL DE INFOBMAÇOES

Antacia do Curitiba

PRONTUARIO N.O

NOME JOSE DO PATROCINIO GALLOTTI

ENDERSCO Avanida Trompowakg ne norianbollo - 80

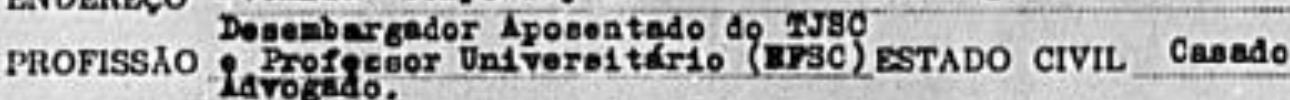

FILIAÇAO Iaudelino Galott1 o de Jul1eta Plasza Calott1

NASCIMENTO

Data Cidado Eatedo Pala

\begin{tabular}{|c|c|c|}
\hline DATA & FONTE & HISTORICO \\
\hline & & 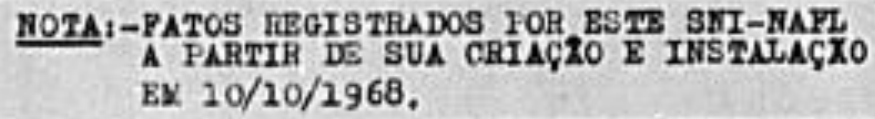 \\
\hline
\end{tabular}

- De concluet̃o do Inquerito in taurado ne UPSC (Univeraidade Pederal de Santa Catarina), apó 1964 no oua cokclusxo, rafletra o a guinte: no reopectivo Relatór1o:

" a) - Alóm do acina exposto, segundo declaraçōos de $\wedge$ DI VIEIBA PILHO, O Profos oor José do Fatrocinio Gallott1, tonava par te $\mathrm{m}$ m reuniōes da Prente Operária Eatudantil Popular, estands presente por ocse1 do de ul tImn reun1to realisoda om 31 de março p. pas budo, ocasião em que foi redigldo violento anifeato de cardter oubveroivo.

"b) - Convóm notar deode já, que figuram no ph seeso, perio1as "grafo-técn1 cas que 1dentifioan a aesinetura do Professor Joes do Patrocinio Gallott1, no Encontro Nacional de Solidariedade à Cuba e da dofasa do principlo de auto-deteranaglo dos povos, bem como na lista de elitores que pleitoavan a volta ì legalidade do Fartido Comunieta. -Conclueĩot 10) que o Frofeseor José do Patrocinio Gallott1 não pode conttruar no exer ofolo de eatedra jú que por sexple to a jatit des, feriu os princip10s do atb Inetsefofós 


\section{Trabalhonecessário}

Issn: $1808-799 X$

ano 14, número $23-2016$

TrabalhoNecessário - www.uff.br/trabalhonecessario; Ano 14, № 23/2016. 


\section{Trabalhonecessário}

Issn: 1808 - 799X

ano 14 , número $23-2016$

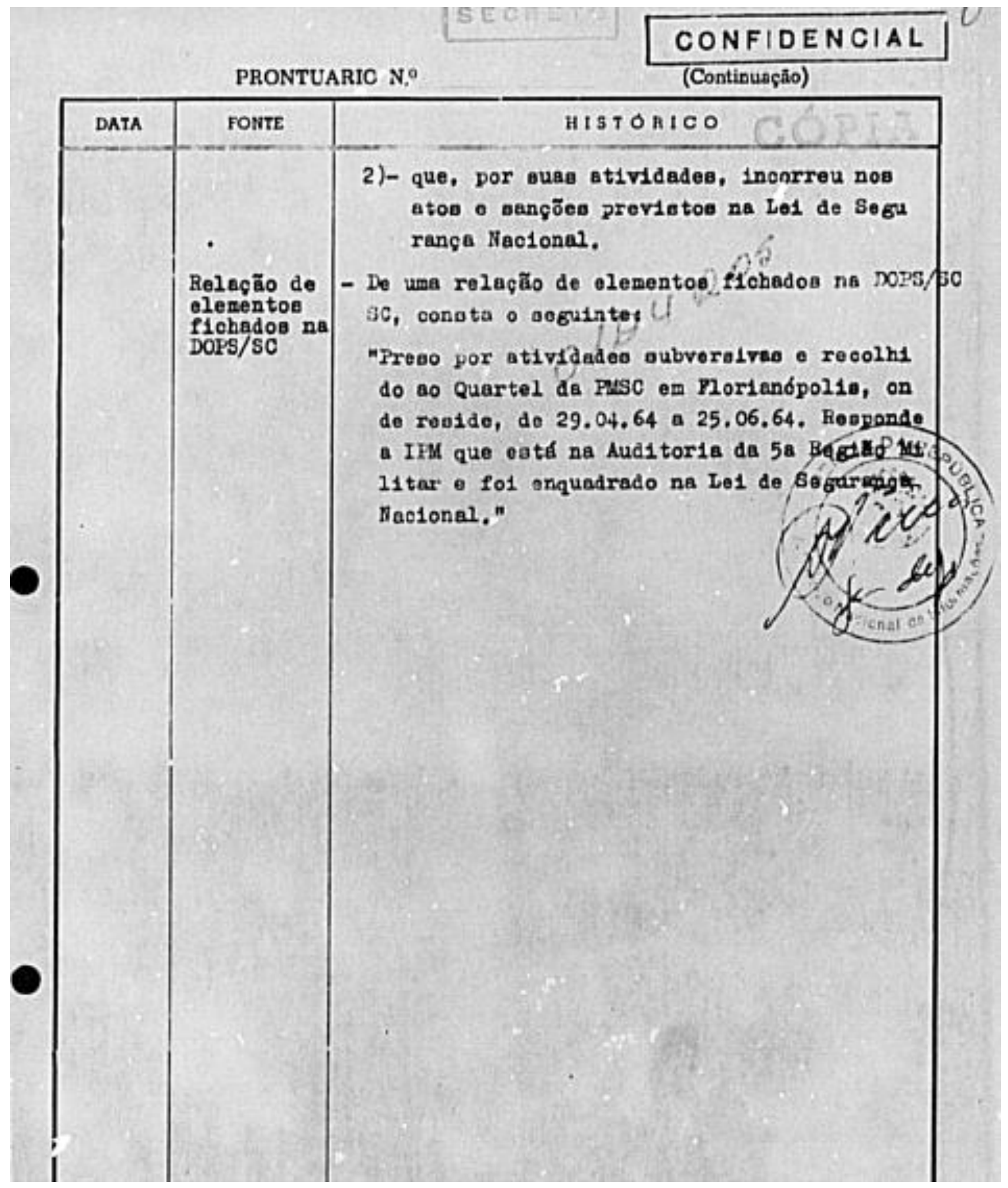

TrabalhoNecessário - www.uff.br/trabalhonecessario; Ano 14, № 23/2016. 


\section{Trabalhonecessário}

Issn: 1808 - 799X

ano 14 , número $23-2016$
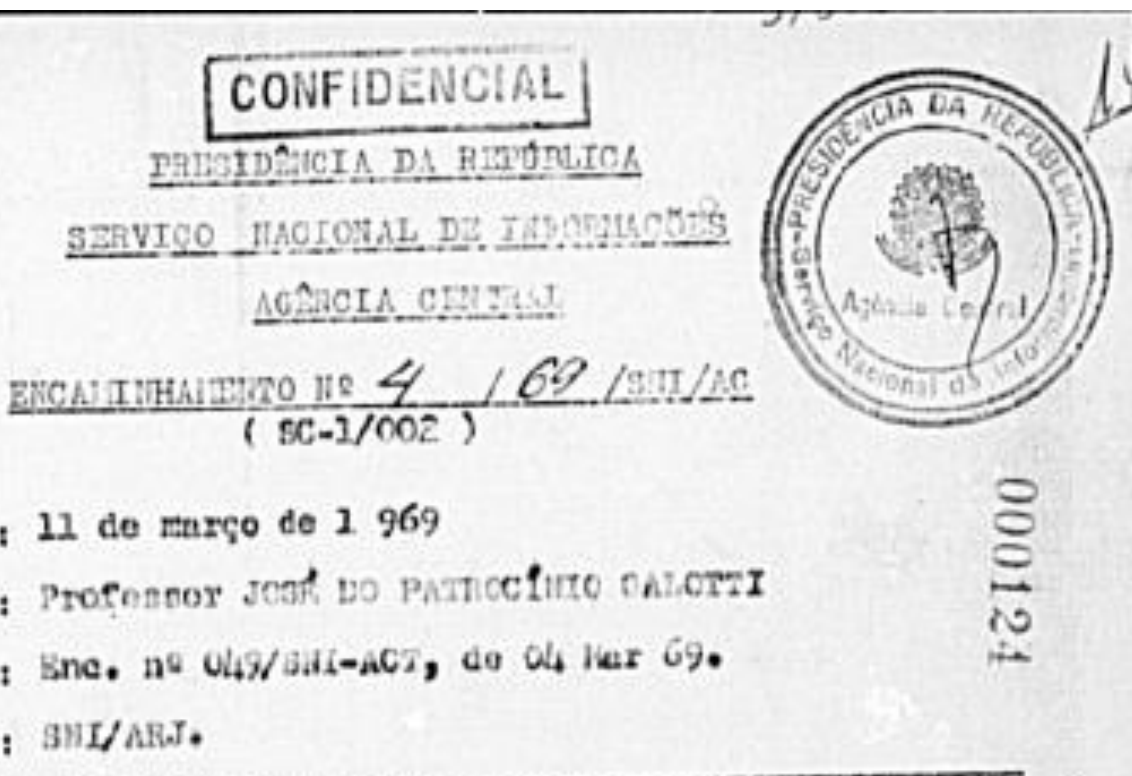

DNTA

Asstrito

REF ERATCIA

a Bne, ne olis adi-aci, do of her 69.

DISTRInUTCRO: BHLART.

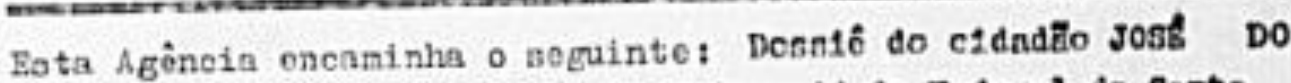

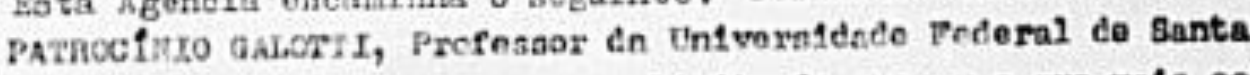
Catarina o docizontos anozos, nolicitanco rnezar o que eals cong

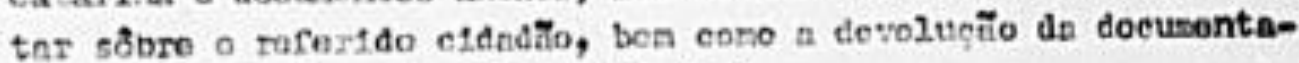
çฐ̃o rosndtente à esta hgånc1 Centrał. 


\section{Trabalhonecessário}

Issn: 1808 - 799X

ano 14, número $23-2016$

Encaminhamento secreto ํo 049, do Sistema Nacional de Informação (SNI), datado de 04 de março de 1969. Fundo SNI. Acervo do Arquivo Nacional.

\section{Considerações finais}

Diante da complexidade do atual momento político brasileiro, em que a direita se endurece e a esquerda não consegue estabelecer estratégia e ação efetiva de resistência, toda análise deve ser muito cuidadosa. No entanto não há dúvidas de que, apesar do estigma criado de desqualificação docente e do descrédito social da carreira, o trabalho docente foi e continua sendo central para a formação de cidadãos críticos. Isso em parte explica a perseguição aos docentes travada no período ditatorial, como também a que se vem observando nos dias atuais, através de interferências dos organismos internacionais, da centralização das decisões efetivada nas secretarias de educação e por movimentos, como o Escola Sem Partido, que não é neutro, mas tem interesses políticos e ideológicos. Nesse sentido, é o trabalho docente, assim como a educação, um espaço/processo contraditório e de luta de classes, ou seja, de disputa por hegemonia.

A influência marxista para análise dos problemas sociais, tão temida desde os tempos ditatoriais, faz com que 0 ato de ensinar busque a raiz das desigualdades sociais, para além das aparências fenomênicas. Nessa direção, grande é a responsabilidade das universidades, espaço em que a maior parte dos docentes é formada, e da escola básica, em que a maior parte dos formados trabalha. Por isso o controle pedagógico das instituições de ensino, pretendido pelo movimento Escola Sem Partido, também tem objetivos para o ensino superior. 


\section{Trabalhonecessário}

Issn: 1808 - 799X

ano 14 , número $23-2016$

Por fim, cabe registrar os debates que se intensificam na Câmara dos Deputados, nas Assembleias Legislativas e em diversas Câmaras de Vereadores, onde o movimento Escola sem Partido propugna "por uma lei contra o abuso da liberdade de ensinar". Tudo indica que os defensores de tal proposta pretendem, na verdade, controlar e despolitizar o trabalho docente, determinando o que pode ou não ser ensinado, tal como no período ditatorial.

\section{Referências bibliográficas}

ALVES, Maria Helena Moreira. Estado e oposição no Brasil (1964-1984). Petrópolis: Vozes, 1985.

BRASIL. Câmara dos Deputados. Projeto de Lei no 876 de 2015. Inclui entre as diretrizes e bases da educação nacional, o "Programa Escola sem Partido". Brasília (DF), 2015. Disponível em: http://www.camara.gov.br/proposicoesWeb/fichadetramitacao?idProposicao=1050 668. Acesso em: 14 mar. 2016.

FERREIRA JR, Amarílio; BITTAR, Marisa. A ditadura militar e a proletarização dos professores. Cedes - Centro de Estudos Educação e Sociedade, v.27, n.97, p. 1159-1179, dez.2006. Disponível em: <http://www.scielo.br/pdf/es/v27n97/a05v2797.pdf>. Acesso em: 12 mar. 2016.

NAGIB, Miguel. Escola Sem Partido - quem somos. Disponível em: <http://www.escolasempartido.org/quem-somos>. Acesso em: 15 mar. 2016.

PANDOLFI, Dulce Chaves. A Aliança Nacional Libertadora e a Revolta Comunista de 1935. In: Os grandes marcos da história política. Vol. II. Rio de Janeiro: BNDES, 2004.2 Disponível em: http://www.bndes.gov.br/SiteBNDES/export/sites/default/bndes_pt/Galerias/Arquiv os/conhecimento/livro_gv/llparte.pdf. Acesso em: 16/03/2016.

REZENDE, Maria José de. A ditadura militar no Brasil: repressão e pretensão de legitimidade 1964-1984. Editora Euel, 2013.

SANTANA, Marco Aurélio. A. Um sujeito ocultado: trabalhadores e regime militar no Brasil. Em Pauta - Teoria Social e Realidade Contemporânea, n. 33, p. 85-96, 1 ㅇ semestre de 2014. 


\section{Trabalhonecessário}

Issn: 1808 - 799X

ano 14 , número $23-2016$

\section{Documentos}

Encaminhamento secreto nํ 049, do Sistema Nacional de Informação (SNI), datado de 04 de março de 1969. Fundo SNI. Acervo do Arquivo Nacional.

Informe no 1587-A4-CIE de 12 de julho de 1983, do Ministério do Exército. Fundo SNI. Acervo do Arquivo Nacional; 